some of the greatest problems of the current generation of reactors.

The existence of the Institute of Nuclear Power Operations (INPO) in the United States, and the World Association of Nuclear Operators, which were created following the Three Mile Island and Chernobyl accidents respectively, are not acknowledged, much less discussed. This is despite the consensus that the INPO has been largely responsible for improvements in the performance of the nuclear power industry in the United States over the past 25 years.

The need for nuclear technologies capable of mitigating global warming - for example, with greater power capacity and fuel breeding - is also not recognized as an essential goal.

Technological subtleties such as uncertainties over future economic performance, the trade-offs between passive and active safety features and the role of human error are at the heart of debates over the best paths for technological development, but Nuclear Renaissance does not examine these issues in any depth.

It does discuss economic deregulation, but fails to explore the role of Britain's more com- pact transmission and distribution structure in the greater success of deregulation compared with the United States. Despite this advantage, nuclear power has been less successful in the United Kingdom than other forms of power generation. BNFL, Britain's nationalized nuclear-power company, currently survives on subsidies from the government. This example raises the question of whether nuclear power plants, with their need for cash even when not operating, are suitable for use in economically deregulated markets.

At the same time, Nuclear Renaissance is far too kind to the opponents of nuclear power, claiming that they have supported the interim storage of nuclear waste at monitored surface sites where terrestrial disposal — as at Yucca Mountain in the United States - is unavailable. This may be true in Britain, but in the United States, anti-nuclear pressure groups have insisted on perfect and immediate solutions to the problem of nuclear-waste disposal. The US nuclear industry has foolishly accepted this impossible challenge.

Finally, Nuttall asserts that greater public knowledge about nuclear power and debate of the issues will help to win acceptance, but I'm not convinced. He does not recognize the alternative hypothesis that the public's approval of nuclear power may depend more on the industry being the three Bs - beneficial, boring and banal - than on intellectual appeals. This hypothesis seems to explain how the public has come to accept other hazardous and previously feared technologies, such as lifts, steam engines and electricity. These opposing hypotheses for public acceptance are worth exploring: knowing which is closer to the truth may be at least as important as developing better hardware.

The book is essential reading for anyone who is interested in the relationship between energy, society and the environment. The author's observations are thought-provoking, and his knowledge of the current energy scene, particularly in Britain, is deep and subtle. So, despite the few warts noted here, this book is a valuable contribution to the debate about nuclear power. You should read it.

Michael Golay is professor of nuclear engineering at the Massachusetts Institute of Technology, Cambridge, Massachusetts 02139-4307, USA.

\title{
A planet tells its story
}

\section{Reading the Rocks: The Autobiography of the Earth \\ by Marcia Bjornerud \\ Basic Books: 2005. 256 pp. \$26, £15.50}

\section{Simon Lamb}

On a recent flight back to Britain from the United States, the person sitting next to me, after discovering that I was a geologist, asked me if it was true that predictions about global warming were just bad science.

I thought of the scientists around the world who had devoted their careers to unravelling the way our planet works and the impact we humans have had on the environment. Are they bad scientists? And then, with a growing feeling of frustration, I realized how effective the smear campaign against environmental science has been, raising doubts in the minds of so many people, lulling them into a false sense of security just at the time when drastic and urgent action has to be taken if humanity is to save itself from the impending disaster.

We certainly need popular science books like Reading the Rocks by Marcia Bjornerud to help science fight back. The book reveals the extraordinary wealth of knowledge that Earth scientists now have about the biosphere and the lithosphere, and the complex interactions between them, that have made this planet the only home for us.

Bjornerud deals with the nature of rocks and the rock record, and what they can tell us about the origins of the Solar System and the subsequent evolution of the Earth's atmos-

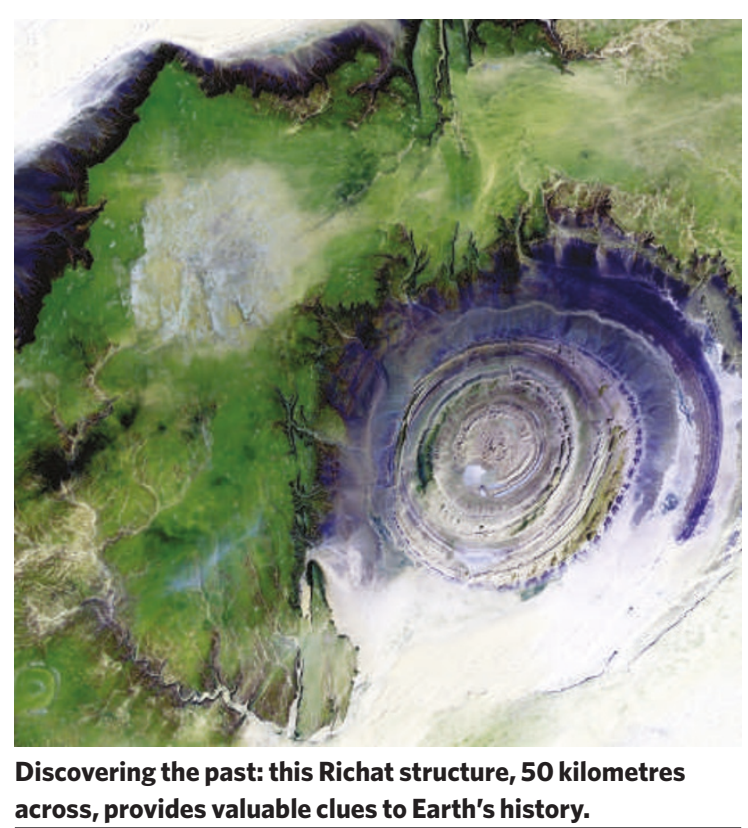

Bjornerud, is a bit like declaring that the fork is the ultimate eating utensil without realizing that half the population of the world find chopsticks even better.

Yet despite my enthusiasm for both Bjornerud's aims and subject matter, I was left with a feeling that the book had missed a trick not because the science was lacking, but because it did not inspire me as much as I felt it should.

I wish Bjornerud had arranged the facts and explanations with more of a sense of an unfolding story about the Earth, the science, and herself and her fellow geologists. When studying the planet's amazing story, the personal quests for understanding, with all the adventures and difficulties along the way, are an overwhelming experience. And these adventures and difficulties create a deeper understanding of the scientific endeavour itself, with its inherent uncertainties.

Nonetheless, Bjornerud tells the phere, oceans and continents, as well as its deep interior. Inextricably linked to all this is the story of life itself. This is the context in which we must consider the effects of our actions on the planet.

The book is well written and Bjornerud has a rare talent for explaining scientific ideas clearly with intriguing and helpful analogies, similes and metaphors. One I rather liked was her riposte to Simon Conway Morris's contention that human intelligence is the inevitable endpoint of evolution. This, says fascinating story of how our planet came into being, with its peculiar restless motion of tectonic plates and the extraordinary role of water, not only in this, but in maintaining the delicate environmental balance that allowed life to evolve over geological time. I only hope we don't go and muck it all up in the next blink of our planet's long history. The planet will survive to tell another story, but we might not. Sciences, University of Oxford, Parks Road, Oxford OX13PR, UK. Simon Lamb is in the Department of Earth 